BMJ Open

Diabetes

Research

\& Care

\title{
Self-administered oral glucose tolerance test with capillary glucose measurements for the screening of diabetes mellitus in high-risk adults: a feasibility study
}

\author{
Andrew Yen Siong Tan (D) , ${ }^{1}$ Mui Suan Tan, ${ }^{1,2}$ Ashley Wu, ${ }^{1}$ Ai Choo Seah, \\ Cecilia Chong, ${ }^{1}$ Eileen Koh, ${ }^{1}$ Ngiap Chuan $\operatorname{Tan}^{1,2}$
}

To cite: Tan AYS, Tan MS, Wu A, et al. Self-administered oral glucose tolerance test with capillary glucose measurements for the screening of diabetes mellitus in high-risk adults: a feasibility study. BMJ Open Diab Res Care 2021;9:e002556. doi:10.1136/ bmjdrc-2021-002556

- Additional supplemental material is published online only. To view, please visit the journal online (http://dx.doi. org/10.1136/bmjdrc-2021002556).

Received 21 August 2021 Accepted 23 November 2021

Check for updates

(c) Author(s) (or their employer(s)) 2021. Re-use permitted under CC BY-NC. No commercial re-use. See rights and permissions. Published by BMJ.

${ }^{1}$ SingHealth Polyclinics, Singapore

${ }^{2}$ Family Medicine Academic Clinical Program, SingHealth Duke-NUS Academic Medical Centre, Singapore

Correspondence to Dr Andrew Yen Siong Tan; andrew.tan.y.s@singhealth. com.sg

\section{ABSTRACT}

Introduction Early diagnosis of prediabetes based on blood sampling for the oral glucose tolerance test (OGTT) is crucial for intervention but multiple barriers hinder its uptake. This study aimed to assess the feasibility and precision of a self-administered capillary 0GTT for type-2 diabetes mellitus (T2DM) in high-risk individuals.

Research design and methods Participants with history of gestational diabetes or prediabetes were recruited in primary care. Due to their prediabetic status and previous diagnosis of gestational diabetes mellitus, a proportion of participants had previous experience doing OGTT. They self-administered the capillary OGTT and concurrently their venous glucose samples were obtained. They filled a questionnaire to collect their demographic information, views of their capillary 0GTT, and their preferred site of the test.

Results Among 30 participants enrolled in this feasibility study, $93.3 \%$ of them felt confident of performing the capillary 0GTT themselves, and $70.0 \%$ preferred the test at home. Older, less educated participants found it less acceptable. Mean capillary glucose values were significantly higher than venous glucose values, with mean difference at $0.31 \mathrm{mmol} / \mathrm{L}(95 \% \mathrm{Cl} 0.13$ to 0.49$)$ at fasting, and $0.47 \mathrm{mmol} / \mathrm{L}(95 \% \mathrm{Cl} 0.12$ to 0.92$) 2$ hours post-0GTT. Capillary and venous glucose measurements were correlated for fasting $(r=0.95 ; p<0.001)$ and 2-hourpost-0GTT $(r=0.95 ; p<0.001)$. The Fleiss-Kappa Score $(0.79, p<0.0001)$ indicated fair agreement between the two methods. The capillary OGTT had excellent sensitivity (94.1\%) and negative predictive value (NPV=91.7\%) in identifying prediabetes or T2DM status, vis-a-vis to venous glucose samples.

Conclusion Self-administered capillary OGTT is feasible and acceptable, especially among younger adults, with excellent sensitivity and NPV compared with plasma-based OGTT.

\section{INTRODUCTION}

Type-2 diabetes mellitus (T2DM) is a growing global disease. ${ }^{1-4}$ Its prevalence is expected to affect 578 million people by $2030 .^{2}$ Early diagnosis of prediabetes (impaired fasting glucose

\section{Significance of this study}

What is already known about this subject?

- Multiple barriers hinder the uptake of oral glucose tolerance test (OGTT) for diagnosis of type-2 diabetes mellitus (T2DM) or prediabetes.

What are the new findings?

- Self-administered capillary OGTT is feasible and acceptable, especially among younger adults, with excellent sensitivity and negative predictive value (NPV) compared with plasma-based OGTT.

How might these results change the focus of research or clinical practice?

- Capillary OGTT may be adopted as a remote screening test, for patients to perform at home safely and conveniently with good level of accuracy.

(IFG) or impaired glucose tolerance (IGT), or both IFG and IGT) is pivotal to retard its progression to T2DM. ${ }^{5}{ }^{6}$ IGT is also associated with an increased risk of microvascular disease. ${ }^{7}$ A 2017 meta-analysis showed that lifestyle interventions targeting patients with IGT resulted in relative risk reductions of T2DM by $26 \%$ and $45 \%$ for shorter $(<3$ years) or longer interventions ( $\geq 3$ years), respectively. ${ }^{6}$ Thus, early diagnosis and interventions in prediabetes will potentially reduce the T2DM burden in the population.

Conventional methods of T2DM screening and diagnosis include assessing the fasting plasma glucose, random HbAlc, or the 2-hour plasma glucose measurement during a $75 \mathrm{~g}$ oral glucose tolerance test (OGTT). ${ }^{89}$ However, the concordance between all three tests is imperfect. ${ }^{8}$ The HbAlc is the most convenient of the three screening tests, which can be easily performed with a finger prick without fasting. Nevertheless, it is 
not recommended in people with gestational diabetes mellitus (GDM), and hemoglobinopathies. ${ }^{8}$ Thalassemia is the most common monogenic disorder worldwide. ${ }^{10}$ HbAlc alone is also a poor biomarker for prediabetes. ${ }^{11}$ Both the HbAlc and fasting plasma glucose assays will miss patients with IGT, leading to underdiagnosis of prediabetes in high-risk populations. ${ }^{12} 13$

OGTT is inconvenient, time-consuming, labourintensive, and relatively costly, and often perceived as unpleasant. ${ }^{14-19}$ Local Asian women with GDM reported 'unpleasant OGTT experience' as a barrier to postpartum T2DM screening. ${ }^{18}$

The challenges of conducting OGTT have prompted the WHO to publish a set of conversion values for capillary and venous plasma glucose values. ${ }^{9}$ Novel methods have been developed to screen T2DM using capillary glucose instead of plasma glucose.$^{20}$ However, the potential of self-administered capillary glucose OGTT remains unknown. Such do-it-yourself (DIY) tests can be carried out at home, which is more convenient.

The current COVID-19 pandemic has highlighted the benefits of telemedicine to minimize exposure risk when visiting healthcare facilities. More patients are willing to use telemedicine during the pandemic. ${ }^{21}{ }^{22}$ Home-based self-performed OGTT can potentially be embedded in the telemedicine framework.

\section{STUDY AIM}

This study aims to assess the feasibility and precision of a self-administered capillary plasma glucose OGTT (cOGTT) to screen for T2DM in high-risk Asian adults. Feasibility is defined to represent the practicality, strengths, and weaknesses of carrying out self-administered glucose testing, and precision can be described as the closeness in measurements for glucose results obtained from different methods. This DIY procedure is postulated to be an acceptable and accurate alternative method to the conventional laboratory-administered OGTT based on venous plasma glucose levels (vOGTT).

\section{METHODS}

Study sites

T2DM screening is commonly performed in primary care. SingHealth Polyclinics is a public primary care institution with a network of eight polyclinics in Singapore serving over 1.3 million residents. The study was carried out at Punggol and Sengkang Polyclinics, located in north-eastern Singapore. These polyclinics manage over 900 patient attendances daily, of which $40 \%-50 \%$ are T2DM-related.

\section{Eligibility criteria of study participants}

The participants included local multiethnic Englishliterate Asian citizens or permanent residents, aged 21 years and above. They comprised women with recent GDM who required postpartum T2DM screening. Another group were adults with prediabetes, defined as
IFG and/or IGT, who were scheduled for an OGTT by their polyclinic physicians.

Adults with pre-existing T2DM, or with mental or physical impairments limiting the self-administration of cOGTT were excluded. The study population included 30 eligible adults, aligned to published guidance on pilot studies as recommended by Lancaster et $a l .{ }^{23}$

\section{Recruitment}

Adults who visited the study sites from March to April 2021 were approached to join the study via convenience sampling. Eligible participants provided written consent and self-administered a standardised questionnaire twice before and after the intervention. Each participant who completed the study received a $\mathrm{S} \$ 20$ (US\$15) voucher in appreciation of their study participation.

\section{Study procedure}

The participants were instructed to fast overnight for at least 8 hours prior to the OGTT. On the test day, each of them was given a standard OGTT kit comprising a bottle of $75 \mathrm{~g}$ glucose solution, lancets, $70 \%$ isopropyl alcohol wipes, an Accu-Chek Performa glucometer (ISO 15197:2013 certified) ${ }^{24}$ glucometer test strips, a countdown timer, and a standardized patient instruction sheet (online supplemental file) on how to self-administer the OGTT. They were instructed to choose the index, middle, or ring finger of their non-dominant hand, wipe the chosen finger with the alcohol swab, and let it air dry before pricking the side of the fingertip with a single-use lancet. They followed a 'no-squeeze' technique to obtain the capillary blood sample.

The participants filmed themselves performing the OGTT (capillary glucose measurement, consumption of $75 \mathrm{~g}$ glucose solution) using camera in their smart phones, while a staff member observed and corrected any errors on the spot. At the start of the procedure, participants performed the cOGTT, while a trained healthcare staff performed the venous blood sampling. The participants then consumed the $75 \mathrm{~g}$ glucose solution (with the healthcare staff ensuring complete consumption) and started the 2-hour countdown timer on their own. After 2 hours, participants completed both the cOGTT and vOGTT.

The self-videos were reviewed on site by an investigator together with each participant. Adverse events and technical errors during the process were recorded by the investigator; these include multiple pricks before blood was obtained due to varying skin and needle thickness, or error messages displayed by glucometers. Venous blood samples were processed at the polyclinic laboratories on-site.

\section{Study questionnaire}

A structured questionnaire was administered in English at the start and end of the entire process to gather participants' demographic information, capillary glucose readings, their assessment of their DIY test using the System 
Usability Scale (SUS), and their preference for the site to conduct OGTT.

The SUS is a globally validated and well-established survey scale used across a wide range of industries to assess the usability of a product or service with a high degree of reliability. ${ }^{2526}$ It was chosen over other scales such as the NASA Task Load Index (NASA-TLX) for its simplicity and its validity across various industries. SUS comprises 10 statements that are scored on a 5-point scale, where higher scores indicate better usability. The last two questions were not applicable in our current study and were excluded, resulting in a maximum score of 80 instead of 100: 'I found the various functions in this system were well-integrated,' and 'I thought there was too much inconsistency in this system'.

\section{Study outcomes}

The primary outcomes were the feasibility and acceptability of a DIY capillary OGTT. Feasibility was determined by refusal and dropout rates, completion rates, adverse events, and error counts. Acceptability was determined by SUS Scores, and patients' preferred place to perform the OGTT. Confidence level in performing the test is self-rated on a 5-point scale. Secondary outcomes were the accuracy and concordance between the cOGTT and vOGTT readings. Sensitivity, specificity, and positive and negative predictive values (NPVs) were used to assess precision of the cOGTT. The sample size has not been accounted for the secondary outcomes of this study.

\section{Statistical analysis}

Results of the OGTT were categorized according to the WHO criteria as normal (fasting glucose $<6.1 \mathrm{mmol} / \mathrm{L}$ and 2-hour post-OGTT glucose $<7.8 \mathrm{mmol} / \mathrm{L}$ ), prediabetes (fasting glucose $=6.1-6.9 \mathrm{mmol} / \mathrm{L}$ and $/$ or 2-hour post-OGTT glucose $=7.8-11.0 \mathrm{mmol} / \mathrm{L}$ ), and possible diabetes (fasting glucose $\geq 7.0 \mathrm{mmol} / \mathrm{L}$ and/or 2-hour post-OGTT glucose $\geq 11.1 \mathrm{mmol} / \mathrm{L}) .{ }^{927}$ The significance of differences between capillary and venous samples was examined by a two-sided paired t-test. Pearson's rank correlation coefficient $(r)$ was used for calculating correlation between all venous and capillary glucose measurements, and scatterplots were used to visualize the relationship between capillary and venous glucose measurements. Using the latter as gold standard, the accuracy of capillary OGTT was assessed by calculating sensitivity, specificity, and positive predictive values and NPVs based on true positive, false negative, true negative, and false positive values. Bland-Altman plots were used to assess the agreement of the two modalities of testing. Fleiss' kappa was used to assess agreement of the two sets of measurements, and values greater than 0.75 may be taken to represent excellent agreement beyond chance, values below 0.4 represent poor agreement beyond chance, and values between 0.4 and 0.75 may be taken to represent fair to good agreement beyond chance. Intraclass coefficient (ICC) was computed to assess the agreement between both methods of glucose testing in

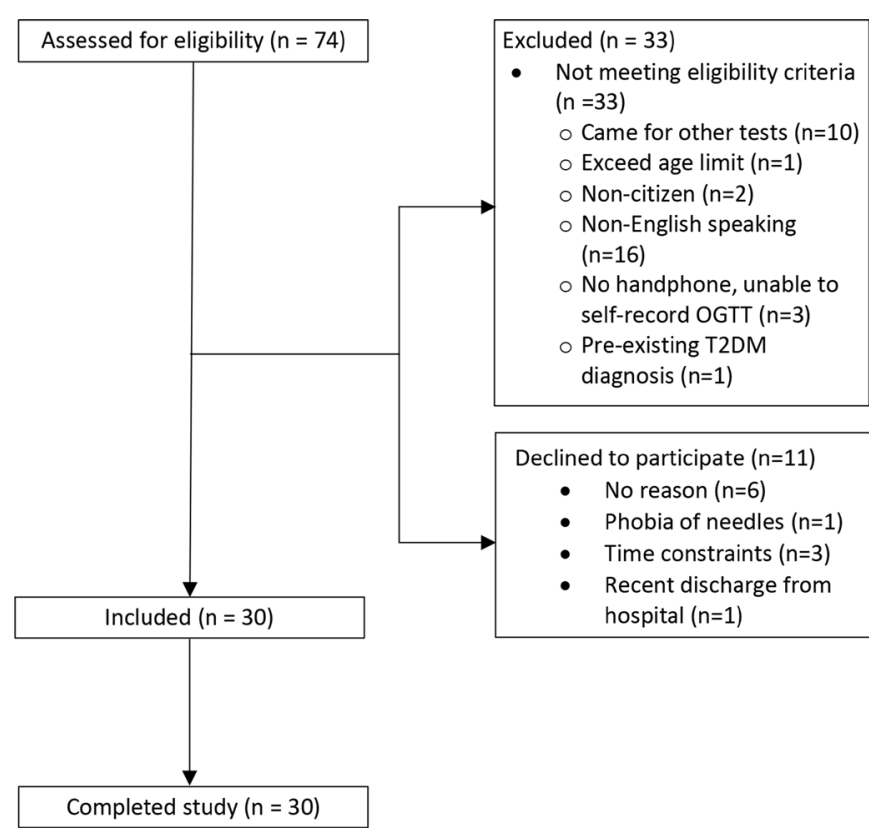

Figure 1 Flow diagram showing study recruitment. OGTT, oral glucose tolerance test; T2DM, type-2 diabetes mellitus.

the 30 participants. A value of $\mathrm{p}<0.05$ was considered as significant. All analyses were performed using R V.4.0.3.

\section{RESULTS}

\section{Subjects}

Seventy-four participants were screened for study eligibility (figure 1), 30 were enrolled, and none was withdrawn from the study. Participants were screened from clinical lab appointment, those with OGTT ordered and met all inclusion criteria were approached on the day of their appointments. Their age ranged from 31 years to 80 years; 17 were women, of which 9 had prior GDM; 18 had previous laboratory-based OGTT experience (table 1).

\section{Primary outcomes}

Eleven patients $(26.8 \%)$ declined to participate in the study. All 30 participants completed the study without any dropouts, withdrawals, or adverse event. Fifteen lapses were recorded among 11 participants (36.7\%), which were namely multiple finger pricks, and blood overflow on the glucometer strips. These 11 participants included $6(54.5 \%)$ aged above 50 years; $8(72.7 \%)$ men; $5(45.5 \%)$ without postsecondary education; and $8(72.7 \%)$ had no prior self-capillary glucose testing experience.

After completing the cOGTT, 93.3\% of the participants felt confident of performing it themselves, $90.0 \%$ perceived it as easy to carry out, $83.3 \%$ perceived readiness in acquiring the technique, and $80.0 \%$ were keen to continue using it (table 2). Their mean self-rated confidence in performing the OGTT themselves was 4.5/5.0 $(\mathrm{SD}=0.63)$ prior to the cOGTT, and 4.4/5.0 ( $\mathrm{SD}=0.93)$ after completing it. The slight decrease in mean confidence score was significant, due to two participants who experienced multiple lapses (multiple pricks and blood 
Table 1 Demographics of study participants, and association with mean modified SUS Scores

\begin{tabular}{|c|c|c|c|}
\hline \multirow[b]{2}{*}{ Demographic } & \multirow[b]{2}{*}{ N (\%) } & \multicolumn{2}{|c|}{$\begin{array}{l}\text { Modified usability } \\
\text { score }\end{array}$} \\
\hline & & Mean (SD) & $P$ value \\
\hline Total & $30(100)$ & $59.1(14.8)$ & \\
\hline Age & & & $0.042^{*}$ \\
\hline $\begin{array}{l}50 \text { years and } \\
\text { below }\end{array}$ & $17(56.7)$ & $63.8(8.6)$ & \\
\hline Above 50 years & 13 (43.3) & $52.9(18.8)$ & \\
\hline Gender & & & 0.512 \\
\hline Male & $13(43.3)$ & $61.2(9.2)$ & \\
\hline Female & $17(56.7)$ & $57.5(18.0)$ & \\
\hline Nationality & & & 0.379 \\
\hline Singapore citizen & 25 (83.3) & $58.0(15.7)$ & \\
\hline $\begin{array}{l}\text { Permanent } \\
\text { resident }\end{array}$ & $5(16.7)$ & $64.5(7.6)$ & \\
\hline $\begin{array}{l}\text { Previous diagnosis of } \\
\text { GDM }\end{array}$ & 9 (52.9) & & \\
\hline Ethnicity & & & 0.856 \\
\hline Chinese & $21(70.0)$ & $58.2(16.4)$ & \\
\hline Malay & $3(10.0)$ & $55.8(13.8)$ & \\
\hline Indian & $4(13.3)$ & $63.1(9.7)$ & \\
\hline Others & $2(6.7)$ & $65.0(10.6)$ & \\
\hline $\begin{array}{l}\text { Highest education } \\
\text { level }\end{array}$ & & & $0.019^{*}$ \\
\hline $\begin{array}{l}\text { None up to } \\
\text { secondary }\end{array}$ & $8(26.6)$ & $47.8(22.5)$ & \\
\hline $\begin{array}{l}\text { JC, ITE and } \\
\text { polytechnic }\end{array}$ & $11(36.7)$ & $60.0(7.07)$ & \\
\hline University & $11(36.7)$ & $66.4(8.2)$ & \\
\hline Occupation & & & 0.378 \\
\hline $\begin{array}{l}\text { Unemployed/ } \\
\text { retiree }\end{array}$ & $7(23.3)$ & $52.1(17.8)$ & \\
\hline Healthcare-related & $3(10.0)$ & $60.8(14.6)$ & \\
\hline $\begin{array}{l}\text { Non-healthcare- } \\
\text { related }\end{array}$ & $20(66.7)$ & $61.2(13.7)$ & \\
\hline Work hours & & & 0.375 \\
\hline $\begin{array}{l}\text { Regular office } \\
\text { hours }\end{array}$ & $18(60.0)$ & $61.0(15.0)$ & \\
\hline $\begin{array}{l}\text { Irregular hours/ } \\
\text { shift work }\end{array}$ & $5(16.7)$ & $62.0(6.0)$ & \\
\hline $\begin{array}{l}\text { Unemployed/ } \\
\text { retired }\end{array}$ & $7(23.3)$ & $52.1(17.8)$ & \\
\hline $\begin{array}{l}\text { Previous OGTT } \\
\text { experience }\end{array}$ & & & 0.199 \\
\hline Yes & $18(60.0)$ & $61.9(13.5)$ & \\
\hline No & $12(40.0)$ & $54.8(16.1)$ & \\
\hline $\begin{array}{l}\text { Previous capillary } \\
\text { glucose test }\end{array}$ & & & 0.072 \\
\hline Yes (done on self) & $12(40.0)$ & $65.0(8.2)$ & \\
\hline
\end{tabular}

Continued
Table 1 Continued

\begin{tabular}{lcll}
\hline & & \multicolumn{2}{l}{$\begin{array}{l}\text { Modified usability } \\
\text { score }\end{array}$} \\
\cline { 3 - 4 } Demographic & N (\%) & Mean (SD) & P value \\
\hline $\begin{array}{l}\text { Yes (done by } \\
\text { someone else) } \\
\text { No }\end{array}$ & $6(20.0)$ & $55.1(17.0)$ \\
& $12(40.0)$ & \\
\hline
\end{tabular}

Statistically significant $(p<0.05)$ are in bold.

GDM, gestational diabetes mellitus; ITE, institute of technical education; JC, junior college; OGTT, oral glucose tolerance test; SUS, System Usability Scale.

overflow on the glucometer strips) during the cOGTT. Both were women aged above 50 years and had no prior experience with self-glucose testing.

At commencement, $21(70.0 \%)$ participants preferred to perform the OGTT at home. It increased to 24 $(80.0 \%)$ immediately after attempting the cOGTT. Of the six participants who preferred the OGTT at the polyclinic, five were above 60 years old; four were men, the remaining two women did not have prior GDM; five were educated up to secondary level; five had no prior self-glucose testing; all had modified SUS Scores (12.5$57.5 / 80)$ that were below the mean $(59.1, \mathrm{SD}=14.8)$ of the study population.

Older participants with lower education levels reported lower mean SUS Scores of the cOGTT than the rest (table 1). All the female higher educated participants with prior GDM were confident and preferred to perform the cOGTT at home.

\section{Secondary outcomes \\ Accuracy}

The mean capillary glucose values are significantly higher than venous glucose values $(6.03 \mathrm{mmol} / \mathrm{L}$ (SD 1.27) vs $5.72 \mathrm{mmol} / \mathrm{L}$ (SD 1.50), respectively, for fasting with $\mathrm{p}<0.001$, and $8.52 \mathrm{mmol} / \mathrm{L}$ (SD 3.48) vs $8.05 \mathrm{mmol} / \mathrm{L}$ (SD 3.88 ), respectively, for 2-hour post-OGTT with $\mathrm{p}=0.042$ ), with the mean difference at $0.31 \mathrm{mmol} / \mathrm{L}(95 \%$ CI 0.13 to 0.49$)$ at fasting, and $0.47 \mathrm{mmol} / \mathrm{L}(95 \%$ CI 0.12 to 0.92 ) at 2 hours after OGTT.

However, a high correlation between the capillary and venous plasma glucose measurements is noted for both fasting $(\mathrm{r}=0.95 ; \mathrm{p}<0.001)$ and 2-hour post-OGTT $(\mathrm{r}=0.95$; $\mathrm{p}<0.001)$. Positive intercepts are found for both capillary and venous samples at all time points in accordance with calculated mean differences. Agreement between both of them is higher at the fasting state than at 2-hour postOGTT (figure 2).

The Bland-Altman difference plots were used to depict differences between the two OGTT methods. Similar to results from the correlation plots, less variation was observed in difference between cOGTT and vOGTT measurements in the fasting state, compared with the 2-hour glucose levels. The plots observed good agreement between the two measurement methods, with less 
Table 2 System usability ratings of self-OGTT

\begin{tabular}{llll}
\hline System usability & (Strongly) Disagree, N (\%) & Neutral, N (\%) & (Strongly) Agree, N (\%) \\
\hline $\begin{array}{l}\text { I felt very confident doing the OGTT myself. } \\
\begin{array}{l}\text { I thought the self-OGTT (finger prick + sugar drink) } \\
\text { was easy to do. }\end{array}\end{array}$ & $2(6.7)$ & $0(0)$ & $28(93.3)$ \\
$\begin{array}{l}\text { I would imagine that most people would learn to do } \\
\text { the self-OGTT very quickly. }\end{array}$ & $2(6.7)$ & $0(0)$ & $27(90.0)$ \\
$\begin{array}{l}\text { I think that I would like to use this self-OGTT } \\
\text { (without the blood-taking from the vein) frequently. }\end{array}$ & $2(6.7)$ & $3(10.0)$ & $25(83.3)$ \\
$\begin{array}{l}\text { I found the self-OGTT (finger prick + sugar drink } \\
\text { only) unnecessarily complex. }\end{array}$ & $15(50.0)$ & $4(13.3)$ & $24(80.0)$ \\
$\begin{array}{l}\text { I needed to learn a lot of things before I could do } \\
\text { the self-OGTT. }\end{array}$ & $17(56.7)$ & $2(6.7)$ & $13(43.3)$ \\
$\begin{array}{l}\text { I think that I would need the support of a technical } \\
\text { person to be able to do the OGTT. }\end{array}$ & $20(66.7)$ & $3(10.0)$ & $10(33.3)$ \\
$\begin{array}{l}\text { I found the self-OGTT very cumbersome to } \\
\text { perform. }\end{array}$ & $23(76.7)$ & $3(10.0)$ & $7(23.3)$ \\
\hline
\end{tabular}

OGTT, oral glucose tolerance test.

than $5 \%$ of points outside the limits of agreement. Two outliers are outside the CIs of both Bland-Altman plots. The plot for the post 2-hour post-OGTT measurements shows increased variations between both methods. The differences between measurements increase with rising glucose levels, exhibiting negative associations in both fasting and post-OGTT states (figure 2).
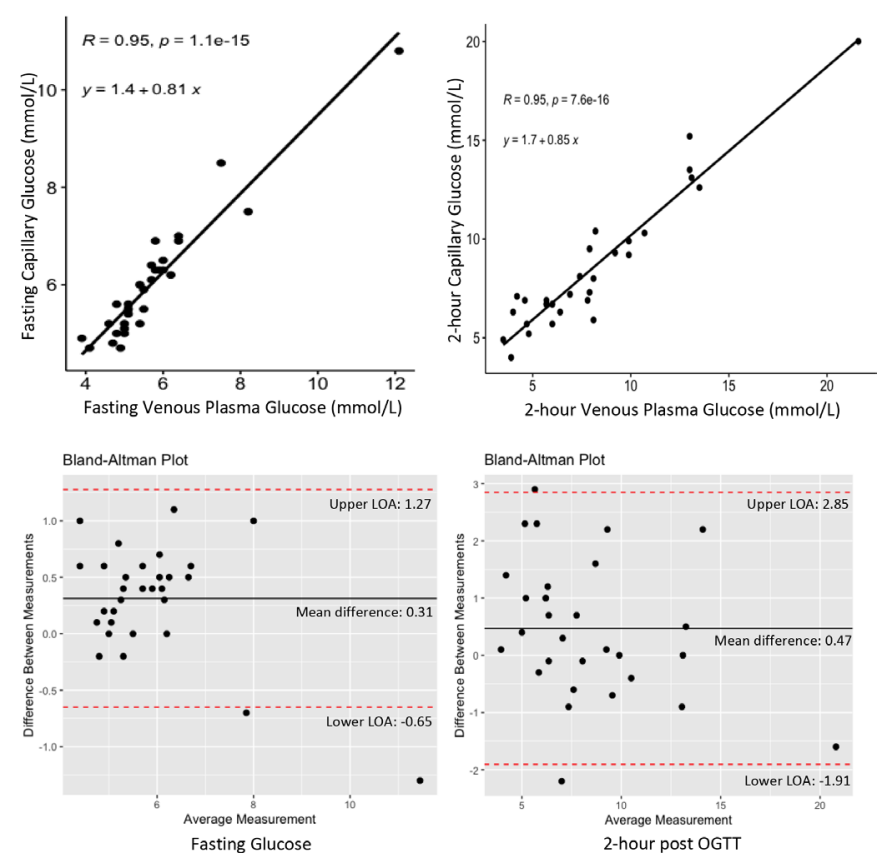

Figure 2 Correlation between capillary and venous plasma glucose measurements - fasting (top left) and 2-hour postOGTT (top right), and Bland-Altman plots for capillary and venous plasma glucose measurements - fasting (bottom left) and 2-hour post-OGTT (bottom right). OGTT, oral glucose tolerance test.

\section{Agreement}

The Fleiss' Kappa Score of $0.79(\mathrm{p}<0.001)$ demonstrated fair agreement between the two methods. The ICC of fasting glucose is 0.92 , and 0.94 for the 2-hour postOGTT glucose level, which indicate excellent absolute agreement between the two methods, based on the twoway random effect models and 'two-way' rater unit.

For categorical results, the cOGTT measurements had a good sensitivity $(94.1 \%)$ and NPV $(91.7 \%)$ in detecting abnormal glucose readings (prediabetes or diabetes range), when compared with concurrently drawn venous plasma glucose samples (figure 3). Only one participant had normal capillary and venous glucose readings (both glucose levels $=5.0 \mathrm{mmol} / \mathrm{L}$ ) but higher 2-hour post-OGTT venous plasma glucose readings (capillary glucose $=7.3$ $\mathrm{mmol} / \mathrm{L}$ versus venous glucose $=7.9 \mathrm{mmol} / \mathrm{L})$.

\section{DISCUSSION}

The cOGTT study had a high acceptance rate of $73.2 \%$, with no dropouts, withdrawals nor adverse events. The error rate of $36.7 \%$ was attributed mainly to older male participants (aged $>50$ years) without prior experience of self-glucose measurements. This study reveals that the cOGTT is feasible in selected groups of patients, such as younger women with prior GDM. The cOGTT was also acceptable to most of the patients, with a mean SUS Score of 59.1 \pm 14.8 (out of max 80). However, those aged above 50 years, and received lower education tended to be less receptive to the cOGTT.

The majority of participants $(93.3 \%)$ had high selfrated confidence (mean confidence score of $4.4 / 5$ ), with $90.0 \%$ of them reporting ease of performing the cOGTT. Most of them $(80.0 \%)$ were keen to continue using the cOGTT and to perform it at home (increase from $70.0 \%$ to $80.0 \%$ after the test). Women with previous GDM were more confident and keen to perform the cOGTT at home 


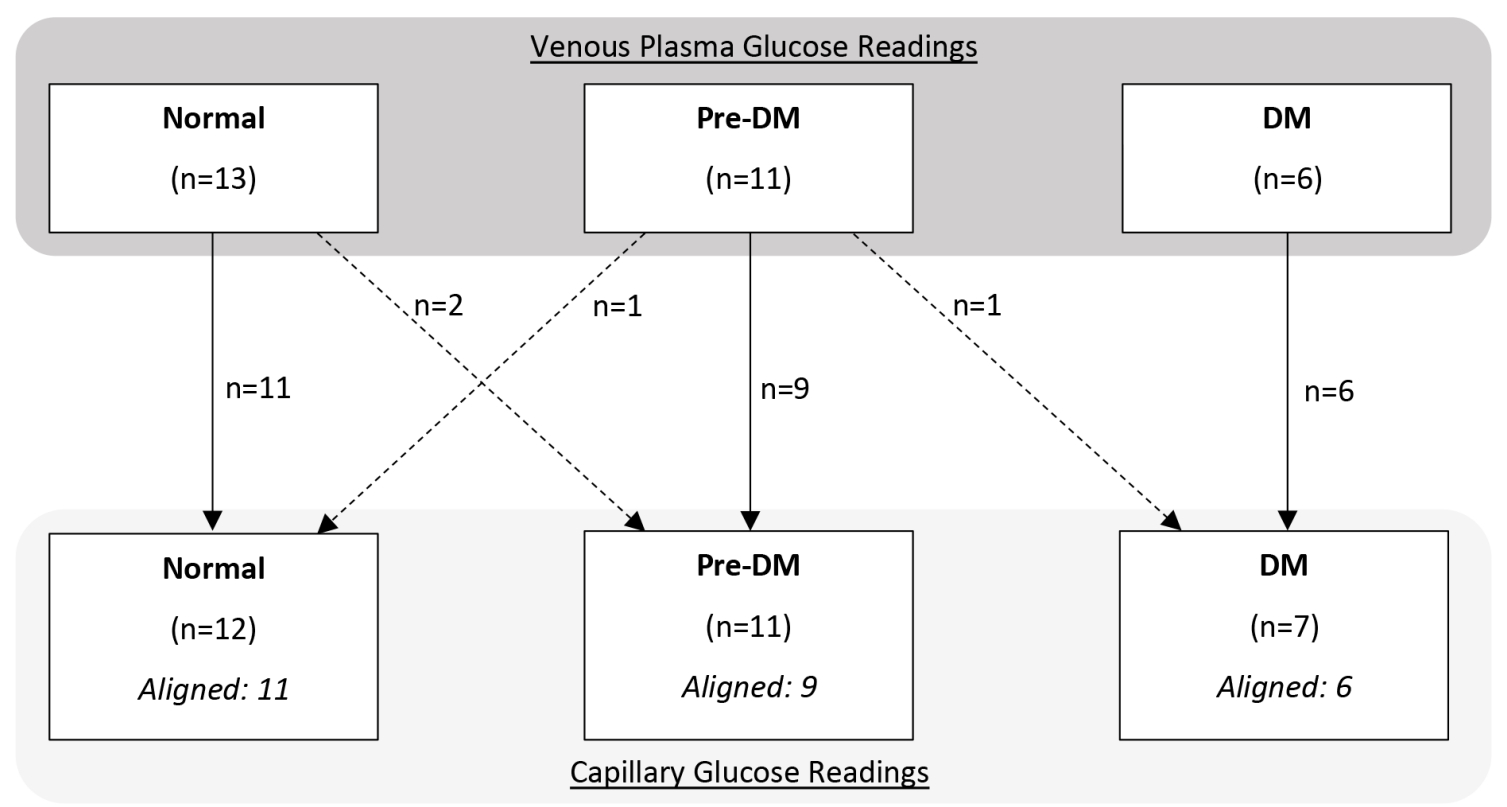

Capillary OGTT in detecting abnormal glucose readings (pre-DM or DM):

Sensitivity $94.1 \%$, Specificity $84.6 \%$, Accuracy $90.0 \%$

Positive Predictive Value (PPV) 88.9\%, Negative Predictive Value (NPV) $91.7 \%$

Figure 3 Comparison of venous plasma and capillary oral glucose tolerance test (OGTT) readings with classification of diabetes mellitus (DM) states.

as they can tend to their infant. Further validation is required to adequately assess feasibility for self-OGTT at home, but current findings allude to self-OGTT's potential as an alternative option to the vOGTT to screen for T2DM among these at-risk women in clinical settings. ${ }^{14-19}$

Our study also shows good sensitivity $(94.1 \%)$ and NPV (91.7\%) for the cOGTT in detecting abnormal glucose readings (prediabetes or diabetes range). The comparability between the cOGTT and vOGTT alludes to the former in identifying people with prediabetes or T2DM. ${ }^{28-32}$ The higher mean capillary glucose values, compared with venous glucose values, potentially identify more people with suspected dysglycemia, while those with normal capillary glucose results are least likely to have wrong diagnosis of prediabetes or T2DM. The results suggest a possible two-tiered approach: those with abnormal capillary OGTT will proceed to the conventional OGTT for definitive diagnosis. In this way, more at-risk adults can be preliminarily screened for T2DM using the cOGTT.

With the increase in telemedicine adoption ${ }^{21} 22$ and an ongoing pandemic limiting physical interactions, more remote screening tests need to be made available for patients to perform them at home safely, conveniently with good level of accuracy. With increasing prevalence of T2DM globally, more home-based T2DM screening tests become imperative for early diagnosis and upstream interventions.

In addition, self-recording of cOGTT using a smartphone can be a form of quality check to avoid fraud or incorrect technique during the test, such as incomplete consumption of the glucose drink. The video recording can be reviewed in real time by trained healthcare professionals via telemedicine or asynchronously if healthcare resources are limited for synchronous monitoring online. With a high smartphone penetration share of $82.3 \%$ in Singapore in $2020,{ }^{33}$ and over half of the adult population (as of 2018) using smartphones to take photos and/ or videos, ${ }^{34}$ implementing a smartphone-linked homebased cOGTT is feasible locally and in countries where Internet of Things is prevalent in their local healthcare settings.

\section{Strengths}

This is a unique study examining the feasibility of a DIY cOGTT for T2DM screening, which can potentially be adapted into a home-based investigation and blended with telemedicine. Concurrent measurements of capillary and venous plasma glucose in this study allowed for additional assessment of the accuracy and concordance between both modalities. Observational data on the error committed during the cOGTT provides information to design better education material and to select suitable subjects when such remote screening tests are scaled across more primary care practices.

\section{Limitations}

The study population was small for a feasibility study and hence generalizability is restricted. Since the sample size is insufficient to evaluate secondary outcomes, we cannot conclude that accuracy results obtained from this study are enough to conclude feasibility. Based on the SUS Scores and patients' responses on self-performing OGTT, it is plausible to apply this in a broader clinical population, 
with additional research to support this claim. However, it provides preliminary insights on the identification and stratification of the potential users who are confident to carry out the cOGTT at home.

Several studies have been conducted over the years to assess the correlation and concordance between venous and capillary glucose measurements, but no clear consensus has been established. While the fasting venous and fasting capillary glucose measurements generally have good concordance, there is greater variability in the postprandial capillary glucose readings. 920 28-30 35-39 Larger studies are also needed to determine the optimal capillary threshold values for prediabetes and T2DM, as these values have been shown to be influenced by the prevalence of T2DM within the target population. ${ }^{29} 303240$

The study was conducted at a polyclinic instead of the residence of the participants. Additional challenges may emerge for an entirely home-based cOGTT, such as the lack of convenient access to glucometers in common households. To address this limitation, future research could consider the application of home-based blood testing delivery system, where users could perform selfcOGTT with a specially designed kit that allow users to send the samples via courier services to labs for testing, in order to address the logistical and technical challenges. A modified SUS was used which limited its usability evaluation of a complete home-based test. An adequately powered trial to validate a two-stage approach with an initial home-based cOGTT followed by subsequent confirmatory vOGTT to confirm diagnosis, targeting at early adopters is in the planning stage.

\section{CONCLUSION}

This study has demonstrated feasibility and acceptability of cOGTT in primary care. Younger participants with previous experience of self-administration of capillary glucose measurements seemed more receptive to this newer modality of T2DM screening. An adequately powered trial is required to validate the values of a homebased cOGTT. While correlation between cOGTT and vOGTT is excellent, further study is needed to identify the optimal capillary threshold values for prediabetes and T2DM in Singapore.

Acknowledgements The authors thank Punggol and Sengkang Polyclinics nurses and laboratory staff for their contribution to making this study possible, and the staff of SingHealth Polyclinics' Department of Research for their support.

Contributors AYST contributed to the designing of the study, development of the questionnaire and patient instruction sheet, analysis of the data, and drafting of the manuscript. NCT contributed to the conception and design of the study, development of the questionnaire, and revision of the manuscript. AYST and NCT are guarantors for the study. MST contributed to the designing of the study, and revision of the manuscript. AW contributed to the data collection, data analysis, and revision of the manuscript. EK contributed to the data analysis, and revision of the manuscript. ACS and CC contributed to the development of the questionnaire and patient instruction sheet, and data collection.

Funding This work was funded by the National Medical Research Council Centre Grant Programme (SingHealth Polyclinics): Integrated Platform for Research in Advancing Metabolic Health Outcomes in Women and Children (I-PRAMHO).
Competing interests None declared.

\section{Patient consent for publication Not applicable.}

Ethics approval This study involves human participants and was approved by the SingHealth Centralised Institutional Review Board (CIRB) CIRB Ref: 2020/3052. Participants gave informed consent to participate in the study before taking part.

Provenance and peer review Not commissioned; externally peer reviewed.

Data availability statement All data relevant to the study are included in the article or uploaded as supplementary information.

Supplemental material This content has been supplied by the author(s). It has not been vetted by BMJ Publishing Group Limited (BMJ) and may not have been peer-reviewed. Any opinions or recommendations discussed are solely those of the author(s) and are not endorsed by BMJ. BMJ disclaims all liability and responsibility arising from any reliance placed on the content. Where the content includes any translated material, BMJ does not warrant the accuracy and reliability of the translations (including but not limited to local regulations, clinical guidelines, terminology, drug names and drug dosages), and is not responsible for any error and/or omissions arising from translation and adaptation or otherwise.

Open access This is an open access article distributed in accordance with the Creative Commons Attribution Non Commercial (CC BY-NC 4.0) license, which permits others to distribute, remix, adapt, build upon this work non-commercially, and license their derivative works on different terms, provided the original work is properly cited, appropriate credit is given, any changes made indicated, and the use is non-commercial. See: http://creativecommons.org/licenses/by-nc/4.0/.

ORCID iD

Andrew Yen Siong Tan http://orcid.org/0000-0001-5438-6453

\section{REFERENCES}

1 World Health Organisation. Global report on diabetes, 2016.

2 Saeedi P, Petersohn I, Salpea P, et al. Global and regional diabetes prevalence estimates for 2019 and projections for 2030 and 2045: Results from the International Diabetes Federation Diabetes Atlas, $9^{\text {th }}$ edition. Diabetes Res Clin Pract 2019;157:107843.

3 Phan TP, Alkema L, Tai ES, et al. Forecasting the burden of type 2 diabetes in Singapore using a demographic epidemiological model of Singapore. BMJ Open Diabetes Res Care 2014;2:e000012.

4 Ministry of Health, Health Promotion Board.. Executive summary on national population health survey $2016 / 17,2018$. Available: https:// www.moh.gov.sg/docs/librariesprovider5/resources-statistics/ reports/executive-summary-nphs-2016_17.pdf

5 Zhuo X, Zhang P, Barker L, et al. The lifetime cost of diabetes and its implications for diabetes prevention. Diabetes Care 2014;37:2557-64.

6 Roberts S, Barry E, Craig D. Preventing type 2 diabetes: systematic review of studies of cost-effectiveness of lifestyle programmes and metformin, with and without screening, for pre-diabetes. BMJ Open 2017;7:e017184.

7 Yudkin JS, Montori VM. The epidemic of pre-diabetes: the medicine and the politics. BMJ 2014;349:g4485.

8 American Diabetes Association. 2. Classification and Diagnosis of Diabetes: Standards of Medical Care in Diabetes-2020. Diabetes Care 2020;43:S14-31.

9 World Health Organisation, International Diabetes Federation. Definition and diagnosis of diabetes mellitus and intermediate hyperglycemia: report of a WHO/IDF consultation, 2006.

$10 \mathrm{Li} \mathrm{C}-\mathrm{K}$. New trend in the epidemiology of thalassaemia. Best Pract Res Clin Obstet Gynaecol 2017;39:16-26.

11 Bai Y, Fang Y, Ming J, et al. Serum glycated albumin as good biomarker for predicting type 2 diabetes: a retrospective cohort study of China national diabetes and metabolic disorders survey. Diabetes Metab Res Rev 2021:e3477.

12 Hu X, Zhang Q, Zeng T-S, et al. Not performing an OGTT results in underdiagnosis, inadequate risk assessment and probable cost increases of (pre)diabetes in Han Chinese over 40 years: a population-based prospective cohort study. Endocr Connect 2018;7:1507-17.

13 Meijnikman AS, De Block CEM, Dirinck E, et al. Not performing an OGTT results in significant underdiagnosis of (pre)diabetes in a high risk adult Caucasian population. Int J Obes 2017;41:1615-20.

14 Stern MP, Williams K, Haffner SM. Identification of persons at high risk for type 2 diabetes mellitus: do we need the oral glucose tolerance test? Ann Intern Med 2002;136:575-81.

15 Van Ryswyk E, Middleton P, Shute E, et al. Women's views and knowledge regarding healthcare seeking for gestational diabetes 
in the postpartum period: A systematic review of qualitative/survey studies. Diabetes Res Clin Pract 2015;110:109-22.

16 Maesa J-M, Fernandez-Riejos P, Sanchez-Margalet V, et al. Fasting glycemia as screening tool to Rule-Out gestational diabetes in lowrisk population. Clin Lab 2018;64:461-5.

17 Sterne VL, Logan T, Palmer MA. Factors affecting attendance at postpartum diabetes screening in women with gestational diabetes mellitus. Pract Diab Int 2011;28:64-8.

18 Sunny SH, Malhotra R, Ang SB, et al. Facilitators and barriers to post-partum diabetes screening among mothers with a history of gestational diabetes Mellitus-A qualitative study from Singapore. Front Endocrinol 2020;11:602.

19 Sanderson H, Loveman E, Colquitt J, et al. Improving uptake of postnatal checking of blood glucose in women who had gestational diabetes mellitus in universal healthcare settings: a systematic review. J Clin Med 2018;8:4.

20 Dunseath GJ, Bright D, Jones C, et al. Performance evaluation of a self-administered home oral glucose tolerance test kit in a controlled clinical research setting. Diabet Med 2019;36:862-7.

21 DYE S, Guo X, Yong DWW. Assessment of willingness to Telemonitoring interventions in patients with type 2 diabetes and/or hypertension in the public primary healthcare setting. BMC Med Inform Decis Mak 2020;20:11.

22 Tan LF, Ho Wen Teng V, Seetharaman SK, et al. Facilitating telehealth for older adults during the COVID-19 pandemic and beyond: strategies from a Singapore geriatric center. Geriatr Gerontol Int 2020;20:993-5.

23 Lancaster GA, Dodd S, Williamson PR. Design and analysis of pilot studies: recommendations for good practice. J Eval Clin Pract 2004;10:307-12.

24 American Diabetes Association. 7. diabetes technology: standards of medical care in Diabetes-2019. Diabetes Care 2019;42:S71 LP-80.

25 Brooke J. SUS: a "quick and dirty'usability. Usability Eval Ind 1996;189.

26 Bangor A, Kortum PT, Miller JT. An empirical evaluation of the system usability scale. Int J Hum Comput Interact 2008;24:574-94.

27 Ministry of Health. Diabetes mellitus: $\mathrm{MOH}$ clinical practice guidelines 1/2014. Singapore, 2014.

28 Kruijshoop M, Feskens EJM, Blaak EE, et al. Validation of capillary glucose measurements to detect glucose intolerance or type 2 diabetes mellitus in the general population. Clinica Chimica Acta 2004;341:33-40.
29 Zhou X, Pang Z, Gao W, et al. Performance of an A1c and fasting capillary blood glucose test for screening newly diagnosed diabetes and pre-diabetes defined by an oral glucose tolerance test in Qingdao, China. Diabetes Care 2010;33:545-50.

30 Liu Y, Guo H, Wang Q, et al. Use of capillary glucose combined with other Non-Laboratory examinations to screen for diabetes and prediabetes. Diabet Med 2019;36:1671-8.

31 Sandbaek A, Lauritzen T, Borch-Johnsen K, et al. The comparison of venous plasma glucose and whole blood capillary glucose in diagnoses of type 2 diabetes: a population-based screening study. Diabet Med 2005;22:1173-7.

32 Agarwal MM, Dhatt GS, Othman Y, et al. Gestational diabetes: fasting capillary glucose as a screening test in a multi-ethnic, highrisk population. Diabet Med 2009;26:760-5.

33 Statista Research Department. Smartphone penetration rate as share of the population in Singapore from 2015 to 2025, 2020.

34 Statista Research Department. Share of population that use Smartphones for life management activities in Singapore as of January 2018, by activity, 2019.

35 Haeckel R, Brinck U, Colic D, et al. Comparability of blood glucose concentrations measured in different sample systems for detecting glucose intolerance. Clin Chem 2002;48:936-9.

36 Brodovicz KG, Girman CJ, Simonis-Bik AMC, et al. Postprandial metabolic responses to mixed versus liquid meal tests in healthy men and men with type 2 diabetes. Diabetes Res Clin Pract 2011;94:449-55.

37 Colagiuri S, Sandbaek A, Carstensen B, et al. Comparability of venous and capillary glucose measurements in blood. Diabet Med 2003;20:953-6.

38 Stahl M, Brandslund I, Jørgensen LGM, et al. Can capillary whole blood glucose and venous plasma glucose measurements be used interchangeably in diagnosis of diabetes mellitus? Scand J Clin Lab Invest 2002;62:159-66.

39 Ignell C, Berntorp K. Evaluation of the relationship between capillary and venous plasma glucose concentrations obtained by the HemoCue glucose 201+ system during an oral glucose tolerance test. Scand J Clin Lab Invest 2011;71:670-5.

40 Haeckel R, Raber R, Wosniok W. Prevalence-dependent decision limits for the early detection of type 2 diabetes mellitus in venous blood, venous plasma and capillary blood during glucose challenge. Clin Chem Lab Med 2006;44:1462-71. 